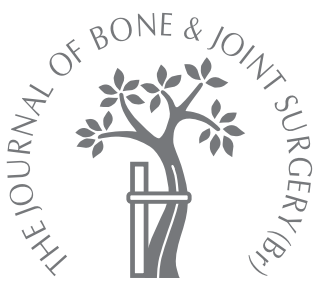

\title{
The use of ultrasound-guided wire localisation in orthopaedics
}

\section{K. Chettiar, N. Sriskandan, S. Thiagaraj, A. U. Desai, K. Ross, D. C. Howlett}

From Eastbourne District General Hospital, Eastbourne, England

K. Chettiar, FRCS, Specialist Registrar (Tr \& Orth) S. Thiagaraj, FRCS, Specialist Registrar (Tr \& Orth)

K. Ross, FRCS, Consultant Orthopaedic Surgeon Department of Orthopaedic Surgery

N. Sriskandan, MRCP, Specialist Registrar in Radiology

A. U. Desai, MRCP, Specialist Registrar in Radiology

D. C. Howlett, FRCR,

Consultant Radiologist

Department of Radiology Eastbourne District General Hospital, Kings Drive, Eastbourne, East Sussex BN21 2UD, UK.

Correspondence should be sent to Dr N. Sriskandan; e-mail: neshe_s@hotmail.com

(C)2009 British Editorial Society of Bone and Joint Surgery doi:10.1302/0301-620X.91B5. $21488 \$ 2.00$

$J$ Bone Joint Surg [Br] 2009;91-B:659-61. Received 3 July 2008; Accepted after revision 4 February 2009

\begin{abstract}
The use of ultrasound-guided wire localisation of lesions is not well described in the orthopaedic literature. We describe a case of an impalpable schwannoma of the femoral nerve and another of sacroilitis with an associated pelvic abscess. In both, surgical localisation was difficult. Peri-operative ultrasound-guided wire localisation was used to guide surgery and minimise tissue damage, thereby optimising the results and recovery of the patient.
\end{abstract}

Ultrasound-guided needle localisation is used to facilitate the excision of breast lesions which are impalpable, particularly those that are not seen during mammography. ${ }^{1}$ The procedure is performed under local anaesthesia and provides real-time imaging of the lesion and guidance of the needle, resulting in fewer complications. It allows focused surgery to be performed which reduces the operating time and minimises trauma to surrounding tissues. ${ }^{1}$ We describe how this localisation technique can achieve the same benefits for deep or inaccessible lesions in the musculoskeletal system, as demonstrated by two separate cases.

\section{Case reports}

Case 1. A 63-year-old woman presented with a six-month history of pain in the left thigh aggravated by squatting. On examination Tinel's sign was positive along the course of the femoral nerve but a lesion could not be palpated. There was no significant past medical history and hip radiographs were normal. MRI of the thigh showed a mass in the mid-anterior compartment (Fig. 1). The lesion measured $2 \mathrm{~cm}$ in diameter and was considered to be consistent with a neuroma, possibly relating to a branch of the femoral nerve.

After discussion with the regional soft-tissue tumour unit it was recommended that the lesion should be excised at our unit. A radiological opinion was sought regarding removal of the tumour because of its small size and deep location. Fine-wire localisation with ultrasound guidance was suggested.

Ultrasonographic identification of the tumour and insertion of the wire were performed in the radiology department under local anaesthesia before surgery. Using an aseptic technique and following local anaesthesia (4 $\mathrm{ml}$ of lignocaine $1 \%$, a small incision was made in the skin. A 19.5 gauge $\times 9 \mathrm{~cm}$ introducer needle was passed under ultrasound guidance to lie just superficial to the lesion, with care taken not to puncture it (Fig. 2). Once the position of the needle tip had been confirmed, the wire was extruded from the needle tip under gentle pressure and deployed in the soft tissue. The barbed configuration of the wire fixed it to the surrounding soft tissue. Ultrasound examination confirmed the position of the wire. Then, under general anaesthesia, a longitudinal incision was made centred on the implanted wire marker. The wire was followed into the thigh musculature and a mobile lump $1 \mathrm{~cm}$ in size was seen arising from a branch of the femoral nerve. This was resected. The patient made an uneventful recovery and had relief from symptoms. Histological examination confirmed that the lesion was a benign schwannoma.

Case 2. A 15-year-old boy presented with a history of worsening pain around the right sacroiliac joint for one week. He was pyrexial with malaise and raised inflammatory markers. There was no history of trauma and no significant past medical history. On examination, he was most comfortable recumbent with his right hip flexed; pain was elicited on springing of the pelvis. Initial pelvic radiographs were unremarkable. MRI of the pelvis showed changes of infective right sacroiliitis with an apparent abscess $2 \mathrm{~cm}$ in size near the inferior aspect of the joint (Fig. 3). Antibiotic medication was started with Fluoxacillin $500 \mathrm{mg}$ qds orally.

Arrangements were made for incision and drainage of the abscess. Initially, a posterior 


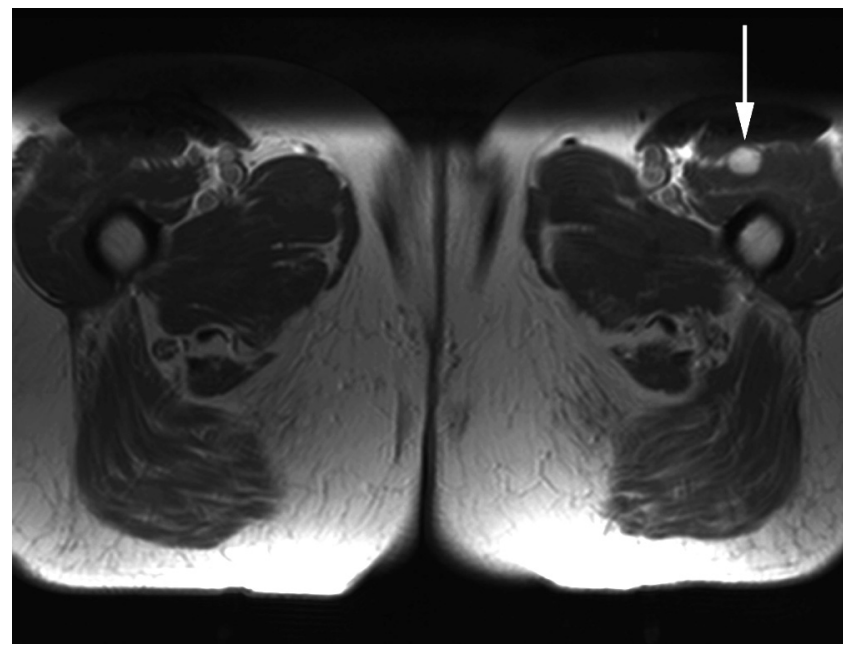

Fig. 1

Axial T1-weighted MR scan of the lower pelvis and both thighs showing a well-defined, high-signal lesion in the anterior compartment of the left thigh (arrow).

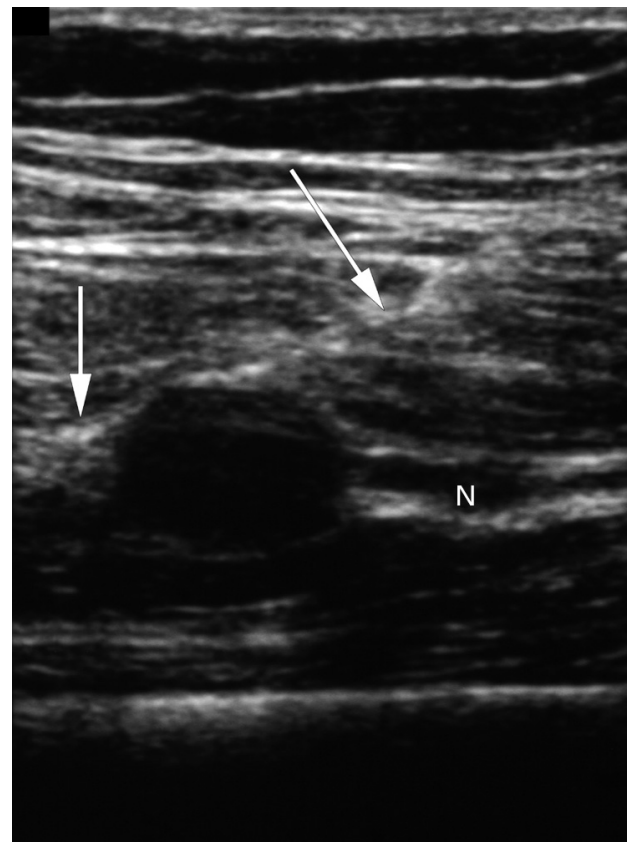

Fig. 2

Longitudinal ultrasonogram showing the hypoechoic rounded nodule arising from the nerve $(N)$ with the localisation wire, represented by the linear hyperechoic structure (arrows) with its tip superficial and adjacent to the nodule.

approach to the hip was used, but the abscess could not be located. A radiologist then attended who demonstrated its presence by ultrasound scanning. Using the posterior approach already made and a similar technique to that in case 1 , a localisation wire was passed into the abscess. The wire was used to determine the site for a second incision

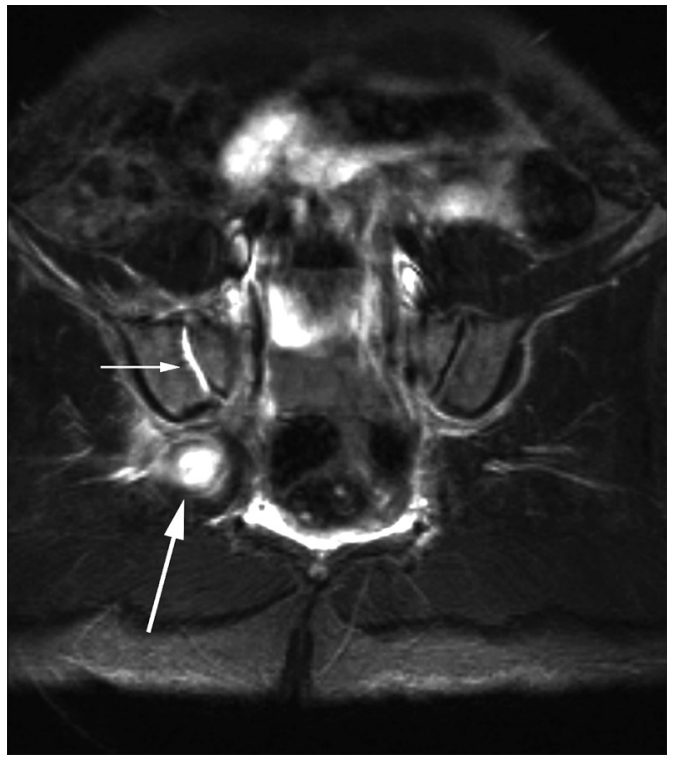

Fig. 3

Oblique coronal STIR MR scan of the pelvis showing a predominantly high signal in the right hemipelvis (large arrow). High signal is also seen within the right sacroiliac joint consistent with fluid secondary to sacroiliitis (small arrow).

behind the sacrum allowing location and drainage of the abscess. Staphylococcus aureus sensitive to flucloxacillin was cultured. He made an uneventful recovery and at follow-up six months later was asymptomatic.

\section{Discussion}

Ultrasound-guided wire localisation is well established in breast surgery. There is little information regarding the use of this technique in orthopaedics. Two small series have described its use to aid the excision of soft-tissue tumours, including neuromas ${ }^{2}$ and intramuscular haemangiomas, ${ }^{3}$ with good results. An example of the use of the technique outside breast surgery is the excision of a thyroglossal cyst. ${ }^{4}$ It has also been used by the authors in excision of a branchial cyst and cervical lymph nodes. ${ }^{5}$

In lesions which are small or impalpable, diagnosis and surgical management may be challenging. This was demonstrated in the case of the schwannoma, which is rare in an extracranial location ${ }^{6-10}$ and in that of the pelvic abscess, which was difficult to access without image guidance. During ultrasound-guided wire localisation, high-resolution ultrasound is used to guide a small-bore (18 or 19.5 gauge) needle either into, or in close proximity to, the lesion under investigation. The needle has a granular coating over its tip (Echotip Cook Ireland Ltd, Limerick, Ireland), which acts to deflect the ultrasound beam, making it echogenic and readily visible sonographically. ${ }^{11}$ Within the needle there is a central hookwire, the tip of which opens out when extruded from the needle tip and fixes the wire in this position (Fig. 4). The wire is thickened distally to give improved 


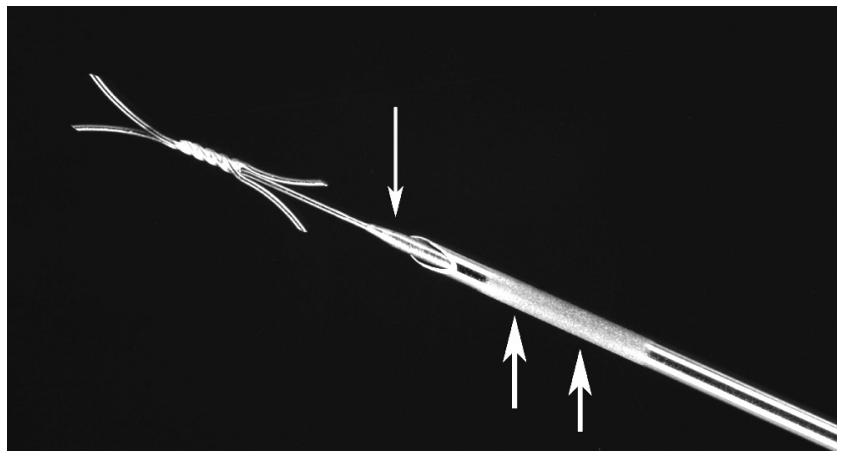

Fig. 4

Photograph of the Echotip needle (large arrows) with the hookwire extruded and its tip opened (small arrow), which fixes it to the surrounding tissue.

intra-operative manipulation allowing assessment of the fixation of the lesion to surrounding tissues. Real-time ultrasonographic examination facilitates accurate positioning of the needle and subsequent deployment of the wire. The introducer needle is retracted, leaving the wire in situ, which once deployed cannot readily be withdrawn back into the introducer. Care needs to be taken during placement of the wire when neoplastic lesions are suspected to avoid puncture and possible spillage of the tumour.

Radiological guidance has often been used in orthopaedics, but usually involves either image intensification or CT. In a similar case, reported by Giannoudis and Tsiridis, ${ }^{12}$ the use of a percutaneous sacroiliac screw-insertion technique in the management of pyogenic sacroiliitis is described. A guide wire was inserted into the sacroiliac joint under image-intensifier control and the joint was then drained. The disadvantage of this technique is the use of radiation for imaging, particularly if the patient is young. Ultrasound guidance was possible in our case since the abscess lay within the soft tissues overlying the sacroiliac joint.
The two cases which we have described demonstrate the versatility of ultrasound-guided wire localisation, which can be performed pre-operatively, either under local anaesthesia in the radiology department or in theatre before excision of the lesion. Pre-operative accurate localisation of the wire increases the confidence of the surgeon, aids operative planning, reduces surgical trauma and improves tissue conservation. ${ }^{13}$ The technique is established in breast surgery and its adoption in orthopaedics should be encouraged, since it has the potential to reduce the risk of peri-operative complications and optimise the recovery of the patient.

No benefits in any form have been received or will be received from a commercial party related directly or indirectly to the subject of this article.

\section{References}

1. Rissanen TJ, Mäkäräinen HP, Kiviniemi HP, Suramo H. Ultrasonographically guided wire localization of nonpalpable breast lesion. J Ultrasound Med 1994;13:183-8.

2. Rutten MJ, Schreurs BW, van Kampen A, Schreuder HW. Excisional biopsy of impalpable soft tissue tumours: US-guided preoperative localization in 12 case. Acta Orthop Scand 1997;68:384-6.

3. Quinn PS, Sieunarine K, Lawrence-Brown M, Tan P. Intramuscular haemangiomas: hookwire localization prior to surgical excision: report of four case. ANZ J Surg 2001;71:62-6.

4. Purayidathil MJ, Manjaly G, Howlett DC. Removal of an impalpable thyroglossal cyst using ultrasound guided wire localisation: a technical note. Clin Otolaryngology 2007:32:141-2

5. Breeze J, Williams MD, Howlett DC. Ultrasound guided localisation during the excision of an impalpable brachial cyst. Br J Oral Maxillofac Surg 2008;46:686-7.

6. Enzinger FM, Weiss SW. Soft tissue tumours. 3rd edition. CV Mosby, 1995:821-88.

7. Katz AD, Passy V, Kaplan N. Neurogenous neoplasm of the major nerves of face and neck. Arch Surg 1971;103:51-6.

8. Gooder P, Farrington T. Extracranial neurilemmomata of the head and neck. J Laryngolotol Otol 1980;94:243-9.

9. Rajagopal KV, Lakhar BN. Solitary giant neurilemmoma in the psoas muscle. Ind J Radiol Imaging 2002;12:551-2.

10. Nawabi DH, Sinisi M. Schwannoma of the posterior tibial nerve: the problem of delay in diagnosis. J Bone Joint Surg [Br] 2007;89-B:814-16.

11. Nichols K, Wright LB, Spencer T, Culp WC. Changes in ultrasonographic echogenicity and visibility of needles with changes in angles. J Vasc Interv Radio/2003;14:1553-7.

12. Giannoudis PV, Tsiridis $\mathbf{E}$. A minimally-invasive technique for the treatment of pyogenic sacroiliitis. J Bone Joint Surg [Br] 2007;89-B:112-14.

13. Moss HA, Barter SJ, Nayagam M, Lawrence D, Pittam M. The use of carbon suspension as an adjunct to wire localisation of impalpable breast lesions. Clin Radiol 2002; $57: 937-44$ 